\title{
The prevalence of femoroacetabular impingement in asymptomatic hips in Indian population: a radiomorphometric analysis
}

\author{
Mohammed Fawas Namboodikandy, Jojo Inassi*, Balaji Zacharia
}

Department of Orthopedics, Government Medical College, Kozhikode, Kerala, India

Received: 07 May 2021

Accepted: 29 July 2021

*Correspondence:

Dr. Jojo Inassi,

E-mail: jojoinassi@gmail.com

Copyright: (c) the author(s), publisher and licensee Medip Academy. This is an open-access article distributed under the terms of the Creative Commons Attribution Non-Commercial License, which permits unrestricted non-commercial use, distribution, and reproduction in any medium, provided the original work is properly cited.

\begin{abstract}
Background: Femoroacetabular impingement (FAI) is a common cause of secondary osteoarthritis of the hip. There are no much studies about the occurrence of FAI in asymptomatic individuals in Indian population. Our objective was to find out the radiological prevalence of FAI in asymptomatic adult Indian population.

Methods: A cross sectional study was carried out in our institution, which is a tertiary care centre, between September 2016 and September 2018 in which in which we studied radiographs of 1600 hips from 800 pelvic x-rays of asymptomatic patients.

Results: Out of 1600 radiographs of the hips studied 1353 were found to be normal and the remaining 247(15.4\%), had features of FAI. 61 hip radiographs (3.8\%) showed cam lesions and $9.2 \%$ showed pincer type of lesion.38 hips $(2.4 \%)$ showed mixed type of FAI.

Conclusions: Significant number of radiographs of asymptomatic patients showed features of FAI. Further long-term studies are needed to see the proportion of these patients with FAI progressing to secondary osteoarthritis of hip.
\end{abstract}

Keywords: Femoroacetabular impingement, Cam type, Pincer type, Secondary osteoarthritis hip, Radiological signs

\section{INTRODUCTION}

Femoroacetabular impingement (FAI)is a recently described hip pathology where there is an abnormal contact between the head- neck junction of the femur and the acetabular rim during movement due to morphological changes in one or both of these structures. ${ }^{1}$ Though the term was coined only in 1999, the descriptions of such morphology can be found to exist in literature for centuries. ${ }^{2,3}$ Chondral damage to hip joint may occur due this altered hip bio mechanics, which in turn initiates a degenerative process which may eventually lead to osteoarthritis. $^{4}$

Three types of FAI are the cam type, pincer type or mixed type, a combination of both. ${ }^{5}$ Cam type of an impingement occurs when an abnormal femoral head with an increasing radius jams into a normal acetabulum during forceful motion, usually flexion. Pincer type is a result of acetabular abnormality usually an acetabular over coverage which results in contact between the acetabular rim and the femoral head neck junction. A mixed one is the result of a combination of these two types. ${ }^{6}$

Diagnosis of FAI is by a combination of proper history, clinical examination and diagnostic imaging. Plain radiographs are useful for evaluating the bony anatomy initially, while CT scan and MRI have roles in surgical planning and definitive diagnosis. ${ }^{7}$ Since FAI has a corelation with later secondary osteoarthritis, an early diagnosis may help prevent its progression.

There are not many reports in the literature regarding the prevalence of FAI in Indian sub-continent. ${ }^{8}$ 
Anthropometric analysis of the hip joint in the south Indian population showed that there is a significant difference in proximal femoral anthropometry compared to the western population and among different regions of the country. ${ }^{9}$ Though it's known that FAI initiates joint degeneration, we don't have data of patients with FAI presenting later with secondary osteoarthritis hip. We hypothesise that FAI could be one of the major causes of secondary osteoarthritis in young adults in our population

Our objective was to assess the radiological prevalence of FAI in the normal population by using pelvic $\mathrm{x}$ rays of asymptomatic population.

\section{METHODS}

A cross sectional study was conducted in our institution which is a tertiary care hospital in south India from September 2016 to September 2018. Radiographs of hips of 800 patients between the ages of 20 and 60 years, attending our outpatient, inpatient and emergency departments were used for the study. We have included all pelvis $\mathrm{x}$-rays which are properly oriented and having adequate exposure. We have excluded all improperly taken $\mathrm{x}$-rays, those with fractures of the hip, previous surgery and old sepsis. Most of the pelvis X-rays were taken for evaluation of low back pain or as a part of the trauma series.

Standard radiographs of the hip including a true anteroposterior view of the pelvis and a cross table lateral radiograph were used in the study. For the standard AP radiograph of the pelvis, with the patient supine on the table with both lower limbs in 15 degree internal rotation, the $\mathrm{x}$ ray beam is centred between a line connecting both anterior superior iliac spines and the upper border of symphysis. The film focus distance was $1.2 \mathrm{~m}$. An x-ray such obtained should have symmetric obturator foramina and the pubic symphysis and coccyx in a straight line with $1-3 \mathrm{~cm}$ between the superior pubic symphysis and tip of the coccyx. ${ }^{10}$

The various radiological parameters looked for were:

Pistol grip sign - a focal prominence of the femoral neck, which leads to a marked loss of the waisting of the femoral head-neck junction and a flattening of its normal concavity. Seen in cam type of impingement. ${ }^{11}$

Cross over sign - Acetabula can be labelled as retroverted or anteverted on the basis of the presence or absence of a crossover or figure-of-eight sign. An acetabulum is considered to be anteverted if the line of the anterior aspect of the rim does not cross the line of the posterior aspect of the rim before reaching the lateral aspect of the sourcil, and retroverted if the line of the anterior aspect of the rim does cross the line of the posterior aspect of the rim before reaching the lateral edge of the sourcil. The Crossover sign refers to over-coverage of the anterior acetabulum due to acetabular retroversion. This is seen in pincer type of impingement. ${ }^{10}$

Coxa profunda - this refers to a deep acetabular fossa. On X-rays, it's seen when the acetabular fossa lies medial to the ilioischial line (Kohler's line). Coxa profunda may cause a pincer type of FAI. This is different from protrusion acetabuli, where femoral head is seen additionally medial to the ilioischial line. All hips that do not meet this criteria are termed "not deep". ${ }^{10}$

Posterior wall sign - indicates insufficient posterior head coverage accompanying acetabular retroversion. ${ }^{12}$ The anterior acetabular ridge is more laterally placed than the centre of femoral head. ${ }^{13}$ This again predisposes to a pincer type of impingement.

Ischial spine sign - When the triangular projection of the ischial spine is visible medially to the pelvic inlet, it indicates acetabular retroversion which predisposes to a pincer type of FAI. This sign has a high sensitivity and specificity even with suboptimal pelvic tilt and pelvic rotation. ${ }^{14,15}$

All the X-rays were evaluated for signs of FAI radiologically using RadiAnt DICOM viewer version 4.6.5.18450 (64 bit).

In the anteroposterior view of pelvis radiographs, we measured coxa profunda, posterior wall sign and crossover sign for detecting pincer type of FAI. Pistol grip sign was used to find out cam type of femoroacetabular impingement. Acetabular inclination was measured. Ischial spine sign was looked for to detect acetabular retroversion.

Study was conducted after getting institutional ethical committee approval. We have obtained the informed consent from the patients for the study and publication.

\section{RESULTS}

We have evaluated 1600 radiographs of hips in 800 asymptomatic individuals presenting to our institution during the period September 2016-2018. Out of the 800 patients, $489(61.1 \%)$ were males and 311 (38.9) were females.

Pistol grip sign, which was an indicator of a cam type of impingement was seen in 99 hips $(6.2 \%)$. Ischial spine sign, suggestive of a retroverted acetabulum was seen in 57 hips (3.6\%). Cross over sign, again a sign of retroverted acetabulum was seen in 46 hips (2.9\%). Of the 1600 hips studied,1551 were "not deep" and in the remaining $49(3.1 \%)$, coxa profunda was noted. In $38(2.4 \%)$ hips, the posterior wall sign was positive. (Table 1)

There were hips with signs of both cam type and pincer type of impingement and these were classified as mixed type. 
Out of 1600 radiographs of the hips studied 1337 were found to be normal and in the remaining $15.4 \%$, had features of FAI. 3.8\% showed cam lesions and $9.2 \%$ showed pincer type of lesion. $2.4 \%$ showed mixed type of FAI (Table 2).

Table 1: Radiologic signs of impingement.

\begin{tabular}{|llll|}
\hline $\begin{array}{l}\text { Radiological } \\
\text { signs }\end{array}$ & Negative & Positive & Percentage \\
\hline $\begin{array}{l}\text { Pistol grip } \\
\text { sign }\end{array}$ & 1501 & 99 & 6.2 \\
\hline $\begin{array}{l}\text { Ischial spine } \\
\text { sign }\end{array}$ & 1543 & 57 & 3.6 \\
\hline $\begin{array}{l}\text { Cross over } \\
\text { sign }\end{array}$ & 1554 & 46 & 2.9 \\
\hline $\begin{array}{l}\text { Coxa } \\
\text { profunda }\end{array}$ & 1551 & 49 & 3.1 \\
\hline $\begin{array}{l}\text { Posterior } \\
\text { wall sign }\end{array}$ & 1572 & 28 & 1.8 \\
\hline
\end{tabular}

Table 2: Prevalence of impingement.

\begin{tabular}{|lll|}
\hline $\begin{array}{l}\text { Type of } \\
\text { impingement }\end{array}$ & $\begin{array}{l}\text { Number of } \\
\text { hips }\end{array}$ & Percentage \\
\hline Cam & 61 & 3.8 \\
\hline Pincer & 148 & 9.2 \\
\hline Mixed & 138 & 2.4 \\
\hline Total & 247 & 15.4 \\
\hline
\end{tabular}

\section{DISCUSSION}

Femoroacetabular impingement has been implicated as an etiologic factor for both acetabular labral pathology and idiopathic arthritis of the hip. The mechanism of labral cartilage damage is excessive shear stresses caused by abnormal bony contact within the hip joint as a result of the abnormal contour of the femoral head-neck junction. ${ }^{5}$

Among the 800 normal population (1600 hips), 1337 hips were found to be normal with no signs of FAI. 61 hips were detected to have cam lesion, 148 hips were found to have pincer lesion and 38 hips had features of mixed type of FAI. The prevalence of FAI in the normal population radiologically was found to be $15.4 \%$ of which $25 \%$ were of cam-type, $60 \%$ of pincer type, and $15 \%$ were of mixed variety.

In a systematic review, the prevalence of an asymptomatic cam deformity was $37 \%$ (range, $7 \%$ to $100 \%$ between studies) and the overall prevalence of asymptomatic hips with pincer lesions was $67 \%$ (range $61 \%$ to $76 \%$ between studies). The athletic population had a higher prevalence in both types. ${ }^{16}$ In another study, a cohort of 110 people without hip symptoms were screened for radiological signs of cam and pincer deformities, with an anteroposterior and cross-table lateral view. The results showed 82 patients $(71.9 \%)$ with at least one radiological sign of cam or pincer deformity, 52 patients $(45.6 \%)$ showed two, and 18 patients $(15.8 \%)$ showed three; none of the patients showed more than three signs. ${ }^{17}$ Here the overall prevalence of FAI $15.8 \%$ is comparable to our present study. Positive cross-over signs were seen in $34 \%$. In our study, this was only $2.9 \%$. Polat et al showed a result of $29.6 \%$ prevalence of FAI in 1076 asymptomatic individuals. $15.9 \%$ of the patients had cam-type, $10.6 \%$ had a pincer type, $3.1 \%$ had combined type FAI and $9.3 \%$ had findings of acetabular dysplasia. This result was much higher than our prevalence but may be considered true for the Turkish population. ${ }^{18}$ In yet another study to assess the prevalence of radiological signs of FAI in 87 Japanese patients, there was a prevalence of $43.6 \%$ dysplasia and $23.7 \%$ pincer lesions. The study was done in radiographs of non-operated sides without arthritic changes in patients who underwent unilateral hip osteotomy. ${ }^{19}$ The radiological prevalence of FAI was studied and it was found that at least one abnormal parameter was present in $66 \%$ of joints, and two or more abnormal parameters were present in $29 \%$ of joints. In seven patients the findings were bilateral. Parameters of mixed morphologic characteristics (cam and pincer) were found in $22 \%$ of joints. $^{20}$ This was also higher compared to the results of our study. Ansari et al screened 100 individuals with AP and lateral $\mathrm{x}$-rays of the pelvis and criteria similar to our study were applied. They reported a prevalence of $5 \%$ of radiological signs of FAI, which amounted to 10 out of 200 hips, 8 of which showed features of both cam and pincer lesions and 2 showed features of pincer alone8.This prevalence value is lower than the value calculated in the present study and is also lower compared to studies conducted in the western population. In another study where prevalence of radiological parameters predisposing to femoroacetabular impingement were compared in young asymptomatic Chinese and white subjects, it was noted that these parameters were significantly higher in white subjects than the Chinese. The cross over sign was more was more prevalent in white subjects in this study. ${ }^{21}$

There are differences in the prevalence of FAI in different populations. The regional social, cultural, and occupational factors may be affecting the prevalence of FAI. Our results may not represent the countrywide prevalence of FAI, since people with different sociocultural backgrounds live in different parts of the country. We think this is one drawback of our study. We have assessed the prevalence of radiological signs of FAI in asymptomatic hips.

All hips with radiological signs may not show clinical features of FAI. Hence our results may not be a true representation of the FAI we see in our practice. Some of the FAI will develop into osteoarthritis in the future, but we cannot predict the fraction of patients getting osteoarthritis of the hip in the future.

We hope that a large-scale prospective study with long follow-up conducted at various geographic locations may answer many of these queries. 


\section{CONCLUSION}

Significant number of radiographs of asymptomatic patients showed features of FAI. Further long-term prospective studies are required to find out how many asymptomatic individuals with radiological features of FAI are developing secondary osteoarthritis in future.

Funding: No funding sources

Conflict of interest: None declared

Ethical approval: The study was approved by the institutional ethics committee

\section{REFERENCES}

1. Leuing M, Beaule PE, Ganz R. The concept of femoroacetabular impingement :current concepts and future perspectives. Clin Orthop Related Res. 2009;467:616-22.

2. Mayers SR, Eijer H, Ganz R. Anterior femoroacetabular impingement after periacetabular osteotomy. Clin Orthopedics. 1999;363:93-9.

3. Matsumoto K, Ganz R, Khanduja V. The history of femoroacetabular impingement. Bone. 2020;9(9):572-7.

4. Hoch A, Schenk P. Thorsten Jentzsch FAI morphology increases the risk for osteoarthritis in young people with a minimum follow up of 25 years Arch Orthop Trauma Surg. 2010;141:1175-81.

5. Ganz R, Parvizi J, Beck M, Leunig M, Nötzli H, Siebenrock KA. Femoroacetabular impingement: A cause for early osteoarthritis of the hip. Clin Orthop Relat Res. 2003;417:112-20.

6. Hong WY, Shon CY, Lee JS. Myung Imaging findings of femoroacetabular impingement syndrome - focusing on the mixed type impingement. Clinical imaging. 2010;34(2):116-20.

7. Tannast M, Kubiak-Langer M, Langlotz F. Noninvasive three-dimensional assessment of femoroacetabular impingement. J Orthop Res. 2007;25:122-31.

8. Ansari. Incidence of femoroacetabular impingement in adult Indian population on the basis of specific radiological findings: a prospective study. International journal of Orthopedic sciences.

9. Sengodan V, Sinmayanantham E, Kumar JS. Anthropometric analysis of the hip joint in South Indian population using computed tomography. Indian J Orthop. 2017;51(2):155

10. Clohisy JC, Carlisle JC, Beaulé PE, Kim YJ, Trousdale RT, Sierra RJ et al. A Systematic Approach to the Plain Radiographic Evaluation of the Young Adult Hip. J Bone Joint Surg Am. 2008;90(4):47-66.
11. LB Laborie, TG Lehmann, Engesæter, DM Eastwood. Prevalence of radiographic findings thought to be associated with femoroacetabular impingement in a population-based cohort of 2081 healthy young adults Radiol. 2011.

12. Reynolds D, Lucas J, Klaue K. Retroversion of the acetabulum. A cause of hip pain. J Bone Joint Surg Br. 1999;81(2):281-8.

13. Stulberg SD, Cordell LD, Harris WH. Unrecognised childhood hip disease: A major cause of osteoarthritis of the hip Proceedings of the third scientific meeting of the hip society. St Louis MO(Mosby). 1975;2128.

14. Kakaty DK, Fischer AF, Hosalkar HS, Siebenrock KA, Tannast M. The ischial spine sign: does pelvic tilt and rotation matter? Clin Orthop Related Res. 2010;468(3):769-74.

15. Kalberer F, Sierra RJ, Madan SS, Ganz R, Leunig M. Ischial spine projection into the pelvis: a new sign for acetabular retroversion. Clin Orthop Related Res. 2008;466(3):677-83.

16. Frank JM, Harris JD, Erickson BJ, Slikker W, BushJoseph CA, Salata MJ et al. Prevalence of Femoroacetabular Impingement Imaging Findings in Asymptomatic Volunteers: A Systematic Review. Arthroscopy: The Journal of Arthroscopic \& Related Surgery. 2015;31(6):1199-204.

17. Their S, Gerisch D, Weiss C, Fickert S, Brunner A. Prevalence of Cam and Pincer Deformities in the XRays of Asymptomatic Individuals, BioMed Res Int. 2017;8562329.

18. Polat G, Şahin K, Arzu U, Kendirci AS, Aşık M. Prevalence of asymptomatic femoroacetabular impingement in Turkey; cross sectional study. Acta Orthop et Traumatological Turcica. 2018;42(1):24953.

19. Fukushima K, Uchiyama K, Takahiro N. Prevalence of radiographic findings of femoroacetabular impingement in the Japanese population. J Orthop Surg Res. 2014;9:25.

20. Chakravarty JK, Sullivan C. Cam and pincer femoroacetabular impingement: CT findings of features resembling femoroacetabular impingement in a young population without symptoms. Am J Roentol. 2013;200:2.

21. Houke JV, Yau WP, Yan CH. Prevalence of radiographic parameters predisposing to femoroacetabular impingement in young asymptomatic Chinese and white subjects $\mathbf{J}$ Bone Joint Surg Am. 201518;97(4):310-7.

Cite this article as: Namboodikandy MF, Inassi J, Zacharia B. The prevalence of femoroacetabular impingement in asymptomatic hips in Indian population: a radiomorphometric analysis. Int J Res Orthop 2021;7:944-7. 